\title{
The Semantic Field of THE ENgLish Modal Auxiliary Can InTERACTING WiTh THE Grammatical Aspect of the Main Verb in Contemporary AmErican ENGLish
}

\begin{abstract}
Existing research recognizes the important role aspect plays in the interpretation of modal readings. This paper presents an empirical approach to this area of study, based on corpus material. The investigation described here is part of the author's large-scale corpus research into modality-aspect interfaces. It traces patterns of interaction as exhibited in the Kratzerian semantic field of the English modal auxiliary can and the grammatical aspects which follow it within matrix predicates. The analyzed language samples were extracted from The Corpus of Contemporary American English (COCA). The study demonstrates patterns of interaction between the modal readings of can and the grammatical aspectual forms of the main verb. Moreover, it also shows that when modality concerns past events expressed through the perfect aspect, it tends to take epistemic conversational backgrounds. In addition to this, this research has also revealed the interaction of modality with subjectival negation.
\end{abstract}

Keywords

modality-aspect interaction; grammatical aspect; modality; modal auxiliary

\section{Introduction}

Modality is a broad concept which has originated in philosophy. In its widest sense, this notion refers to the relationship between the uttered proposition and the world. Since language constitutes a means of expressing modality, this phenomenon has also received considerable attention from philosophers of 
language and linguists (e.g. Abraham and Leiss (eds.) 2008, Bybee et. al. 1994, Hacquard 2009, 2011, 2013, Kratzer 1991, 2012, Lyons 1977, Palmer 1979/1990, 1986/2001, Portner 2009).

The present paper discusses selected elements of empirical, corpus-based research, in which the author traces the paradigm of modality-aspect interaction (Szymański 2019). Numerous attempts to resolve this issue have been made (Abraham 2008, Abraham and Leiss (eds.) 2008, Hacquard 2009, Kotin 2012, 2014). Most of the existing research, however, has tended to recognize aspect from the dichotomous viewpoint perspective, i.e. scholars view events as either perfective or imperfective. The present study investigates the interaction of modality with the category of aspect viewed from the grammatical perspective (Binnick 1991, Comrie 1976/2001, Sasse 2002).

It has been observed that modal auxiliaries interact with aspect (and also with tense) because of their anaphoric reference (Hacquard 2013). In the study described below, the phenomenon of the modality-aspect interfaces is exemplified with the English modal auxiliary verb can and the possible verb forms which follow it within matrix predicates.

This paper has been divided into two parts: the first one establishes the theoretical background and the other one presents the analysis. The former opens with a concise characterization of the notion of modality. This is followed by a description of the theoretical framework of the semantic field of modal expressions (Kratzer 1991), which has been chosen to portray the patterns of the investigated modality-aspect interaction. The next section delineates the concept of grammatical aspect which the study referred to below addresses. Further, the practical part of this paper begins with an introduction of the analyzed material, followed by a description of the research procedure. Next, the article presents and discusses the study results. Eventually, the conclusion summarizes the research findings.

\section{Modality}

The concept of modality derives from philosophy, where it is considered a very broad issue. For logicians, modality, in its broadest sense, relates to the modifications people make to facts of which the world is composed (Nuyts 2006, Perzanowski 2006).

Modality may be expressed by means of various linguistic devices, such as: verbs, adjectives, adverbs or mood. Hence, this philosophical-logical concept has also been studied by linguists. Numerous semantic accounts perceive modality as, for example, "the speaker's opinion or attitude towards the proposition that the sentence expresses or the situation that the proposition describes" (Lyons 1977: 452). According to another view, modality relates to the notions of possibility and necessity; i.e. whether the event denoted by the proposition is or was necessary or possible, to varying degrees (Kratzer 1991, 2012, von Fintel 2006). 
This study refers to the latter of the above ways of understanding modality, which corresponds to the domain of the modal force in the model of the semantic field of modal expressions (Kratzer 1991), which is described below. Moreover, the current research narrows the concept of logical modality down to grammatical modality (Harcquard 2013), as it focuses on the modal auxiliary can.

\subsection{The semantic field of modal expressions}

The study described in the present paper uses the model of the semantic field of modal expressions (Kratzer 1991). This framework has been chosen in order to investigate the interaction of the semantic features of the English modal auxiliary can with the grammatical aspect of the main verb. The proposed theoretical model is composed of three hierarchically-organized domains: modal force, modal base and ordering source, which are presented below.

The first domain is the modal force. It is the strength of the relationship between the uttered proposition and a group of other propositions. There are two types of the modal force distinguished: possibility and necessity. This division may be exemplified by the following sentences:

(1) Peter could see the accident.

(2) Peter must have seen the accident.

The above examples show the possibility/necessity dichotomy. In (1), the speaker takes into account the circumstances and states that there existed a possibility for Peter to see the accident. The possibility may be due to the fact that Peter was at the given time in the place where the accident happened; so the circumstances in which Peter was made it possible for him to see the accident. Example (2) expresses the speaker's conviction that a certain event took place in the past, here: Peter did see the accident. It may be interpreted that, in view of what the speaker knows, there existed a necessity, or it cannot be otherwise than, that Peter saw the accident.

The second domain is the modal base. It refers to the conversational background which provides all the available information supplied by the context of the expressed proposition. Such information forms the basis for the interpretation of modality in the particular situation.

The above-said information may take two distinct origins. On the one hand, the modal reading may be derived from the situation to which the speaker refers in the proposition. Such modal bases are termed circumstantial, for instance:

(3) Passengers must fasten their seat belts.

Example (3) demonstrates the deontic meaning of obligation. It is imposed in a situation when a person becomes a passenger of a given vehicle. Thus, the 
circumstantial modal base in (3) relates to the passengers' position in a vehicle, where the seat belts are required to be fastened. This is enforced by the traffic code and highly recommended for safety reasons. The circumstances the speaker refers to include both the setting in which the passengers are, as well as the rules they are expected to obey.

On the other hand, certain modal meanings may come from the speaker's knowledge, opinion or belief. These are labeled as epistemic and may be exemplified as follows:

(4) Tom must be at home. His car is in the driveway.

This example shows how modality is expressed on the basis of the speaker's reasoning. Since Tom's car is parked in the driveway, supposedly in front of the house he lives in, the speaker concludes that it is necessary, or it cannot be otherwise than, that its owner is at home. Hence, since this modal interpretation is derived from the speaker's assumption or opinion about what the world is like, it belongs to the realm of epistemic modality.

The third domain of the discussed model is the ordering source. This is a second conversational background which imposes an ordering on the group of available worlds in which possibilities and necessities are evaluated; and it influences the interpretations of modal meanings. This second conversational background was introduced so as to avoid interpretational confusion which may occur because of other propositions which may influence the modal reading (Kratzer 1991: 647-648). Each of such conversational backgrounds constitutes a possible world, i.e. the way the world could have been (Chrzanowska-Kluczewska 2013, Hintikka 1962, Pruss 2001).

As Kratzer (1991: 649) points out, circumstantial modals are structured by sources related to laws, aims, plans or wishes; whereas epistemic modals take their ordering sources in the normal course of events, reports or beliefs. These in turn allow for numerous interpretational possibilities, as Kratzer observes (1991: 649). This argument has prompted us to adopt the following labels for the ordering sources in our interpretations (see also Szymański 2019: 25-26):

- abilitive - for the agent's inherent characteristics which enable one to act in a certain way;

- boulomaic - for one's wishes or desires;

- permissive - for a permission granted by an authority in certain circumstances;

- empty - for the speaker-external circumstances (circumstantial modal bases) or for the speaker's knowledge (epistemic modal bases);

- deductive - for the modal reasoning that comes from observable evidence

- speculative - for the modal reasoning that comes from the speaker's speculations not based on evidence

- doxastic - for the speaker's belief 
The above terms are based on what Kratzer (1991: 650) calls the ordering sources for the German modals she uses to exemplify the model of the semantic fields of modal expressions.

\subsection{The classification of modals}

The Kratzerian framework of the semantic field of modal expressions provides a further ground for a typological classification of modals. This approach comes from the dual nature of the modal base. The modal readings which emerge from the circumstantial factors form the category of root modals; whereas those whose meaning is derived from factors based on opinion, knowledge or belief form the category of epistemic modals (Kratzer 1991: 650). Thus, the former include the meanings of obligation, permission or ability, and the latter include the meanings of necessity, possibility or probability coming from one's reasoning (after Sweetser 1982: 484).

\section{Aspect}

A large body of literature dealing with the category of aspect has been published (see e.g. Binnick 2002-2006 or Sasse 2002). This term is said to originate from Slavic linguistics. The word aspect is a direct translation of the Russian word вид [vid], which denotes a view or vision (after Binnick 1991: 136, Sasse 2002: 210, 212).

In linguistic tradition, aspect is an element of time semantics. This notion denotes the way in which the internal temporal constituency of a situation is viewed (after Comrie 1976/2001: 3). This, in turn, may be expressed in natural languages in two manners: by means of grammatical constructions and via the semantics of a verb phrase.

Traditional literature on aspect distinguishes between: the viewpoint and the semantic aspect (Binnick 1991, 2006, Comrie 1976/2001, Dahl 1985, Ekhoff and Haug 2015, Smith 1997, Sasse 2002). The former relates to how a situation is perceived in terms of its completeness or incompleteness, and thus it sees situations in a binary manner as either perfective (completed) or imperfective (not completed). The viewpoint aspect is generally expressed by grammatical (or morphological) means. When it comes to the semantic aspect, it is included in the intrinsic temporal characteristics of a situation denoted by a verb or a verbcomplement phrase. The Anglo-American aspectological tradition derives the semantic aspectual categories from the concepts proposed by Vendler (1957), which are perceived as the prototypical lexical aspectual classes for English (after Sasse, 2002)

Throughout this paper, aspect is approached from the grammatical (morphological) standpoint; and it is, therefore, referred to as grammatical aspect. This term covers grammatical constructions which may be perceived as carriers of 
aspectual meanings (see Binnick 1991, 2005, 2006, Comrie 1976/2001, Higginbotham 2009, Huddleston and Pullum 2002, Quirk et al. 1985 or Sasse 2002). As far as the English language is concerned, the following types of the grammatical aspect may be distinguished: simple, progressive, perfect, perfect progressive, prospective, retrospective and habitual. Since this analysis relates to the interaction of a modal auxiliary with the grammatical aspect, the focus of the study will be narrowed down to those constructions which may follow a modal auxiliary in a matrix predicate, namely: the simple, the progressive, the perfect and the perfect progressive aspects. These are presented below.

To begin with, the simple aspect (also referred to as the simple verb (Dahl 1985) or the neutral aspect (Smith 1997)) is expressed by an aspectually unmarked form of the verb (Quirk et al. 1985). This form does not provide any information about the duration, completeness or incompleteness of an event. These should be interpreted at the contextual level. Nevertheless, the simple aspect encodes the non-progressive and non-perfect aspectual readings (Huddleston and Pullum 2002: 124). Next, the progressive aspect is built from the auxiliary verb be followed by the present participle of the main verb. This aspectual form typically expresses the ongoing nature of an event. Hence, it may be perceived as a bearer of imperfectivity. Then, the perfect aspect is composed of the auxiliary verb have followed by the past participle of the main verb. This form expresses the retrospective viewpoint of an event. In addition to this, it denotes non-progressive events (see Szymański 2019). It is important to remember that the perfect is not the same as the perfective. Finally, the perfect progressive aspect is constructed from two auxiliaries: have and the past participle of be - been, plus the present participle of the main verb. This structure expresses the ongoing nature of the event denoted by the main verb, which occurs as dynamically progressing before a certain point in time. Thus, the perfect progressive combines the perfect with the progressive.

\section{Methods}

\subsection{Source of language material ${ }^{1}$}

Our study was carried out with the use of language material excerpted from The Corpus of Contemporary American English (COCA) (Davies 2008-). The language samples were obtained from the online version of the corpus available at https://corpus.byu.edu/coca/ (accessed in January, 2019).

The corpus includes over 570 million words. It is composed of 220,225 texts produced or published in the United States from 1990 to 2017. The texts are grouped on the basis of the genre they represent. In this way, one can additionally access 5 sub-corpora: spoken, fiction, popular magazines, newspapers and academic journals. Table 1 shows the overall numerical specification of the text types included in the corpus. 
Table 1. The numbers of words per genre in The Corpus of Contemporary American English.

\begin{tabular}{|l|c|}
\hline \multicolumn{1}{|c|}{ genre } & number of words \\
\hline Spoken & $118,167,133$ \\
\hline Fiction & $113,404,735$ \\
\hline Popular magazines & $118,450,563$ \\
\hline Newspapers & $114,341,164$ \\
\hline Academic journals & $111,537,393$ \\
\hline TOTAL & $570,353,748$ \\
\hline
\end{tabular}

\subsection{Research procedure}

The present investigation looks for the potential patterns of interaction between can and the grammatical aspect of the main verbs. For one thing, the study analyzes how the aforesaid interaction is expressed in the semantic field of the modal (Kratzer 1991). Moreover, the study categorizes these findings according to the typological dichotomy of modal readings classified between root and epistemic (Kratzer 1991, Sweetser 1982).

The potential patterns of interaction were traced in the authentic manifestations of language excerpted from The Corpus of Contemporary American English (Davies 2008-). The intention was to investigate how the conversational backgrounds, that is the modal bases and the ordering sources, correlate with the different grammatical aspectual forms of the main verbs.

For the purpose of the study, sentences with the modal auxiliary can in their matrix predicates were extracted from the corpus and analyzed. From the outset, the aim was not to include predicates with negation, because negation is another category with which modality interacts (see e.g. de Haan 1997). This was not of the primary interest in this analysis (cf. Szymański 2016a, 2016b, 2017).

The researched language samples were extracted with the use of the following query strings: can [vvi] for can with the simple aspect, can [vvg] for can with the progressive, can have [vvn] for can with the perfect and can have been [vvi] for can with the perfect progressive. This is how the lists of examples for the analysis were obtained. They included the following three types of matrix predicates:

$$
\begin{aligned}
& \text { can }+ \text { [simple aspect] } \\
& \text { can }+ \text { [progressive aspect }] \\
& \text { can }+ \text { [perfect aspect] }
\end{aligned}
$$

The query for can followed by the perfect progressive did not manage to find any instances of these matrix predicates in the corpus. Therefore, this construction was not explored. Table 2 lists the frequencies of the aforesaid types of matrix predicates in $C O C A^{2}$. 
Table 2. Frequencies of matrix predicates with the modal auxiliary can retrieved from The Corpus of Contemporary American English.

\begin{tabular}{|l|r|}
\hline \multicolumn{1}{|c|}{ matrix predicate } & frequency \\
\hline can + [simple aspect] & $100,000+$ \\
\hline can + [progressive aspect] & 1251 \\
\hline can + [perfect aspect] & 85 \\
\hline can + [perfect progressive aspect] & 0 \\
\hline
\end{tabular}

There was, however, a technical limitation imposed by the online corpus software. It put a restriction on the number of the analyzed items in the form of a list saved online. Because of this, a list of at most 100 occurrences of a particular construction could be saved and retrieved, even though the search provided more results.

\section{Analysis and discussion}

This part of the present paper addresses the issue of the interaction within the semantic field of the modal auxiliary can and the above-mentioned grammatical aspects: simple, progressive and perfect consecutively. The study focuses only on the scope of the modal's operation.

The modal meanings of can reported in this study do not differ from those described, for example, in Biber et al. (1999/2007), Coates (1983), Huddleston and Pullum (2002) or Kratzer (1977). Thus, we will concentrate on the dichotomy between circumstantial (root) and epistemic meanings, which hinges upon the modal bases. The former meanings of can include: ability, permission and possibility; whereas the latter include possibility based on the speaker's reasoning. In this study, the modal meanings are perceived as achieved as a result of the interaction of the three dimensions of the semantic field.

\section{1. can + [simple aspect]}

This section explores the patterns of interaction within the semantic field of the modal auxiliary can followed by the simple aspect. All of the excerpted examples have been reported to express the modal force of possibility, for example:

(5) Felicia Hutchinson (left) is the fastest jumper on the Indy Air Bears. She can jump 300 times in one minute!

As for the modal force expressed in (5), in view of certain circumstances, it is possible for the agent to jump 300 times in one minute. This possibility comes from the fact that, in the circumstances the speaker refers to, the agent has this bodily ability and is fit enough to perform this type of physical activity, which creates the said possibility for her. 
As far as the modal base is concerned, the studied sample has provided examples of circumstantial modality exclusively, for instance:

(6) At the end of the night, people who don't want to go home can book a room at the Renaissance.

(7) Using your very own John Paul II cutout doll, you can create your favorite papal ensembles

In each of the examples quoted above the possibility comes from the situation in which the particular agent is present. The context in (6) refers to a post-Oscar party held at the Grand Ballroom to celebrate the Academy Awards. Since the ball finishes late at night, the attendees have the possibility of booking rooms at the Renaissance hotel. Thus, this possibility comes from the circumstances in which the said hotel offers vacant rooms which may be reserved by the ball participants (see Szymański 2019: 121). Next, example (7) refers to a situation in which one can make a paper doll of the pieces of paper provided by the toy producer. The modal interpretation in this sentence comes from the circumstances in which it is possible to use parts of the cutout doll to build various ensembles one desires, including the one of the Pope. This is possible due to the design of the doll and the parts provided by the toy producer. Hence, the modal evaluation is situation-based.

When it comes to the ordering sources influencing the circumstantial modal readings of can followed by the simple aspect, this study has identified four types.

First of all, the situation-dependent modal reading of can followed by the simple aspect may come from the agent's ability, as it is in:

(8) Cacioppo believes that people can overcome loneliness, even chronic loneliness.

The possibility in (8) comes from the ability that the agent has. It is believed by Cacioppo that, in general, people have the skills and the knowledge about how to use them in order to defeat loneliness successfully. Moreover, this ability may be activated if the circumstances the agent is in require it. Hence, the ordering source is abilitive in this case.

Then, the circumstantial readings of can followed by the simple aspect may be governed by the permissive ordering source, for instance:

(9) Students can affect their probability of remaining in the course by engaging in more favorable academic behavior.

Example (9) comes from college regulations. According to this document, under the therein stipulated circumstances, it is possible for students to remain in the course. This possibility is granted by an authority in the codified regulations, and it comes from the fact that the college authorities give their permission to the 
students who fulfill the additional, imposed requirements (see also Szymański 2019: 162).

Next, one may also enumerate the boulomaic ordering source among those influencing the modality in the matrix predicates with can and the simple aspect. This may be exemplified as follows:

(10) Andrew, if I can ask you -- you cover this region.

In (10), the speaker asks Andrew's permission, or, in other words, the speaker wants Andrew to allow him to ask about some information. Hence, as the possibility comes from the speaker's desire to ask a question, the ordering source may be recognized as boulomaic.

Finally, the empty ordering source has been distinguished. This may be exemplified as follows:

(11) You can ride me until we find the first horse-the one that throwed herand then you can mount up proper.

In (11), the possibility comes from the circumstances to which the speaker refers. The situation in question will take place when the said first horse is found. This will create the possibility to "mount up proper". Therefore, as this possibility is dependent on the available circumstances external to the speaker, the ordering source is labeled empty.

\section{2. can + [progressive aspect]}

When it comes to the matrix predicates with the modal auxiliary can followed by the progressive aspect of the main verb, out of the 100 excerpted instances, only 32 could be studied in terms of modality-aspect interfaces. This is so because in the remaining 68 occurrences, the alleged present participles of the main verb forms have been recognized as adjectives denoting the characteristics of nouns, for example:

(12) And while alienation and desolation can be wearying topics, Johnston's airy arrangements and fragile melodies make the journey more healing than harrowing.

Query results like (12) may be motivated by the fact that there is no formal distinction between the progressive verb form, the adjective, and also the gerund; all of which take the -ing morpheme. This could have brought about the mistagged lexical items in the corpus. In spite of this limitation, the analysis of the remaining matrix predicates with can followed by the progressive aspect has allowed us to establish a number of facts. 
To start with, can in all those matrix predicates expresses the modal force of possibility, for instance:

(13) I can be going to a game all of a sudden. I just throw something in bag. All of a sudden, it's creativeness, you know. Just creativeness is here. Put that in there, put that in there. OK. Great. Here I am. Check me out!

Example (13) comes from an interview with Dennis Rodman, a basketball player. Accused by his interlocutor of being "contrived", Rodman denied and stated as it is outed in (13). For him, it is possible to "be going to a game all of a sudden". This possibility comes from his skills related to playing basketball, also from the fact that he is physically fit and strong enough, as well as that he has all the four limbs. All of these make it possible for him to perform the said action (see also Szymański 2019: 103).

When it comes to the modal base, 18 of the analyzed matrix predicates with can and the progressive aspect have been reported to express circumstantial modal readings and the remaining 14 have been interpreted as epistemic. The former include:

(14) You can be accessing funds and moving funds without your name being attached to it.

(15) But it is far more social in that two or three of you can be sitting along a couch watching the same program.

Example (14) refers to the circumstances in which it is possible for the agent to make financial operations without their name being assigned to them. This is possible because some banks offer such untraceable operations; hence, it is the circumstances that provides the possibility for such actions (see also Szymański 2019: 164). Then, in (15), the possibility of sitting along the couch and watching television for those two or three people is provided by the circumstances. This may be due to the commonly shared room or apartment, as well as because of the organization of the furniture in the room, or even as the two or three people may have such a desire (see also Szymański 2019: 103).

With reference to the epistemic readings of can with the progressive, one may find the following examples:

(16) "Oh god: Hank. Really, that's all I need. So I can be traveling down there with two angry teenagers."

(17) "If we choose to take the right steps, there is every reason to believe that 10 years from now multiple private entities can be taking payloads and passengers on a for-profit basis to suborbital space and to orbital space (...)." 
The possibility expressed in (16) derives from the speaker's reasoning, in which he deduces his potential future activity. The modal evaluation is based on what the speaker knows about his companions-to-be and their anticipated behavior. Then, example (17) presents a situation in which the speaker speculates about a possibility in the future. This speculation comes from the speaker's prediction or anticipation about what may potentially happen under the circumstances in which the right steps are taken.

As far as the ordering sources are concerned, for the circumstantial readings of can followed by the progressive aspect, three types have been observed.

Firstly, circumstantial readings of the discussed matrix predicates have been found to come from the ability, for example:

(18) Those are good things, and that's all I can be thinking about right now.

Here, the speaker refers to a possibility which comes from his ability to perform the mental activity of thinking at the very moment. Therefore, the ordering source is abilitive (see also Szymański 2019: 165).

Secondly, the circumstantial readings have been found to derive also from permissive ordering sources, for example:

(19) You say, you say your favorite favor to your passengers is helping the unaccompanied minors. I, I can't believe children as young as 5 can be flying alone on one of your flights.

The circumstantiality in (19) refers to a situation taking place on a plane of a certain airline to which the utterance is addressed. The possibility in this example comes from the hypothetical permission that the airline, as an authority in this situation, grants to children (here: at the age of 5 years) to travel without an accompanying adult.

Thirdly, one may also distinguish the empty ordering source, where the possibility comes purely from the circumstances, like in:

(20) My wife can be rattling a few pots in the kitchen six feet from where I am sitting, and it almost makes me want to jump.

This utterance comes from a patient's letter to a doctor, in which the former describes his problem as being bothered by not very loud sounds. In this example, the possibility expressed by the modal can comes from the circumstances in which the agent (here: the patient's wife) is present, that is the kitchen in their house. These circumstances include the location of the agent in the kitchen, as well as the equipment available there, which produces the rattling noise. One may also consider an abilitive ordering source here; however, the hypothetical ability of rattling the pots may not be used by the agent purposely. 
When it comes to the epistemic modal readings of can followed by the progressive aspect, the deductive ordering source has been identified, for example in (16). Also, the speculative ordering source has been distinguished. This is illustrated by the following instance:

(21) It was professionally disappointing in that I think law firms are slow in recognizing the upcoming aging of baby boomers and the growing number of lawyers who can be contributing to those firms.

Example (21) shows how the modal reading of can depends on what the speaker thinks about the potential world. Here, the opinion the speaker has may be attributed to their speculation about the potential future contribution of the lawyers to the companies.

\section{3. can + [perfect aspect]}

Although there are grammar books which say that can is not used with the perfect aspect of the main verb (e.g. Vince 2008: 96), the studied language corpus has proved the opposite. This is so because the search for can + have + [perfect participle] has provided 85 hits in COCA.

Out of the excerpted 85 results, 35 turned out not be instances of the searched predicate construction. That was so because the alleged past participle verb forms in the perfect aspect have been reported to function as adjectives, for example:

(22) Information systems now enable new work configurations that can have foreseen and unforeseen effects.

The above stems form the fact that English does not use a formal distinction between a past participle and an adjective. Hence, the lexical items may have been mistagged in the corpus. In addition, the past particle has been found to be the the main verb in the causative constructions following the modal, for example:

(23) Then there are safe rooms, the minibunkers that security-concerned homeowners can have installed for anywhere from $\$ 25,000$ to $\$$ 50,000 .

Let us now turn to the modal matrix predicates with can followed by the perfect aspect of the main verb. The study has found that the modal force expressed by can in these constructions may be either necessity (17 occurrences) or possibility (33 occurrences).

As for the modal force of possibility expressed by the modal auxiliary can in matrix predicates with the perfect aspect of the main verb, it can be found in: 
(24) Because changes in, a lead to changes in Esubb, the fine-structure constant can have changed by at most a few percent since decoupling.

Here, the writers (two authors of an article) express that, in view of certain information or speculations, it was possible that the fine-structure constant has changed by at most a few percent (see also Szymański 2019: 108).

When it comes to the modal base, all the instances of possibility expressed by can followed by the perfect aspect take epistemic modal bases. This may be exemplified by:

(25) I do not know where he can have come by such a notion, but he was so earnest in his concern that both James and I had difficulty in keeping a sober expression.

In the above-quoted example, the modal reading of possibility comes from the knowledge the speaker has about the world. The speaker expresses their doubtful conclusion about the possibility that "he" had ever found the said "notion" (see also Szymański 2019: 177).

When it comes the ordering sources, the conclusion expressed in (25) comes from the speaker's speculations about the world which may have existed for the agent. Therefore, in (25), one may identify a speculative ordering source.

Moreover, the modal can followed by the perfect may take the deductive ordering source. Consider the example below:

(26) There is also some evidence that individual vLPAs can retain unusually intact species assemblages and significant populations of particular species of regional or global conservation concern, and they can have marked regional conservation significance.

In (26), the writers' (the text has two authors) modal reasoning may stem from their conclusion. Their interpretation of the possibility is based on the knowledge they probably have about how such $v L P A s$ (very Large Protected Areas) have worked in other places or how they typically work. Thus, they draw their conclusion from such evidence, which makes the ordering source deductive.

When it comes to the modal force of necessity, it has been found, for example, in the following sentences:

(27) Few doctors nowadays can have seen a carbuncle like this.

(28) No category of antiques can have generated a more spurious mythology than that surrounding Irish glass.

Both sentences (27) and (28) express the speakers' certainty (or conviction) that in view of what the speakers know it is necessary, or in other words: it cannot be 
otherwise than, that: in (27), not many physicians have seen a carbuncle like the one being discussed, and in (28), there has not been a category of antiques which has generated the said type of mythology.

As for the modal base, all the instances of necessity expressed by can in the matrix predicates with the perfect aspect take epistemic modal bases. Consider the following example:

(29) Not many messages can have made it through from the universe I find myself in.

Sentence (29) exemplifies how the necessity expressed by the modal can takes the epistemic modal base. In this case, the speaker is convinced that, at the utterance time, there are not many messages which have survived. This conviction comes from the knowledge or opinion which the speaker has about the world. Thus, the modal base is epistemic.

The ordering sources have been recognized as speculative or deductive. They are exemplified below:

(30) The book made Jack Kerouac forever synonymous with tales of the highway, and few other novels can have caused so many restless people to wander their nation contemplating the nature of existence.

(31) No one in the history of literary theory can have written so much with such seriousness on the subject of play.

In both examples (30) and (31), the modality expressed by can comes from the opinions the writers (both of the quotes come from written sources) have about the world. In both the cited utterances, the modal readings of can take the writers' speculations as their ordering sources. They rely on what the writers speculate the situations may have been like. Moreover, in both these cases, it is also possible that the ordering sources are the writers' deductions. This may be so when the opinions expressed by them are based not on pure speculations, yet on certain evidence they know, have or can observe. Thus, the ordering source in (30) will be deductive when the writer has the knowledge about the real effect the "few other novels" they refer to have had on "so many restless people". In the same way, the can in (31) will take a deductive ordering source when the writer bases their opinion on their factual knowledge of other writers' works contrasted against the works of the discussed writer in the history of literary theory (see also Szymański 2019: 112).

What is important to notice here is the fact that in all the sentences with can expressing the modal force of necessity the subject is negative: "few doctors", "no category of antiques", "not many messages", "few other novels", "no one in the history of literary theory" (see also Szymański 2019). In all these examples, the negative element precedes the subject. Therefore, as it is not a constituent of the 
matrix predicates, the negator does not influence the proposition. Nonetheless, it does affect the modality. The fact that the expressed modal force changes from the prototypical possibility to necessity clearly shows that modality interacts with negation (de Haan 1997, J. Payne 1985, T. Payne 1997, Morante and Sporleder 2012, Szymański 2016a, 2016b, 2017). In this case, however, it is the negation of the subject, not of the verb. Consequently, it may be deduced that the influence of negation which results in its interaction with modality does not necessarily need to involve the predicate negation. It takes place also with the negation of the subject of the sentence. This needs more detailed further analyses.

\section{Conclusions}

The study described above was designed to establish the potential patience of interaction in the semantic field of the English modal auxiliary verb can in matrix predicates with various grammatical aspects expressed by the forms of the main verbs, within the scope of the modal's operation. The analysis presented above was carried out on language samples excerpted from the $C O C A$, and it constitutes an element of a larger project on modality-aspect interfaces.

The current research has confirmed that modality interacts with the grammatical aspect, and this interplay is manifested in the domains of the Kratzerian semantic field of the modal auxiliary can. Moreover, certain patterns of modalityaspect interfaces have been found. They are presented in Table 3.

Table 3. The research results

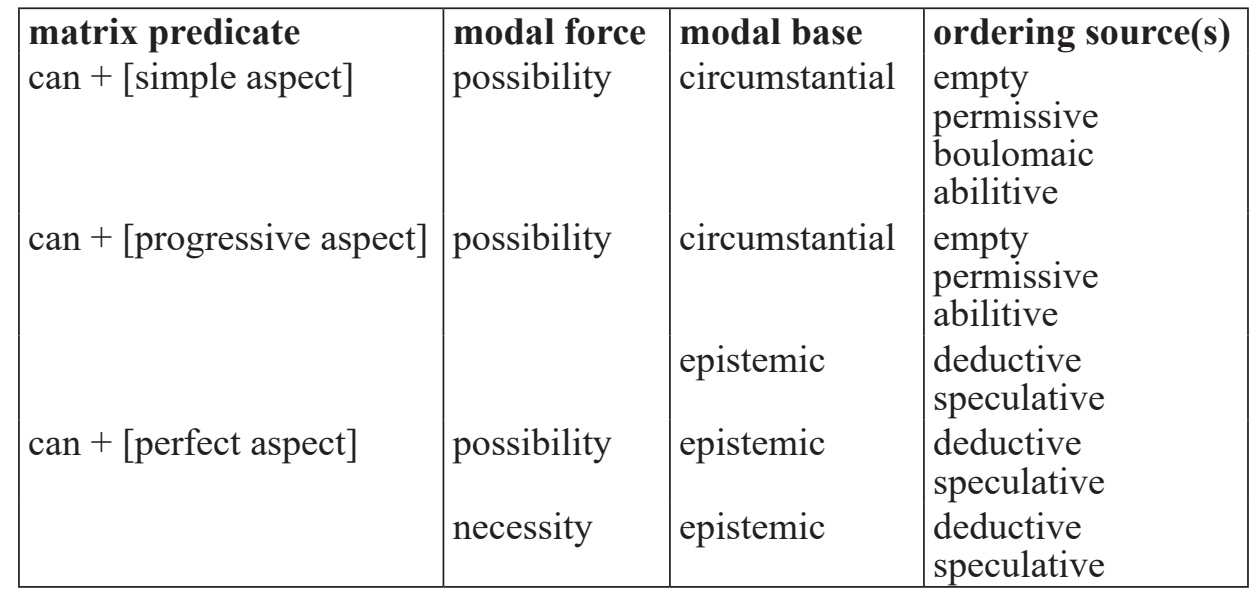

First of all, in matrix predicates with the simple aspect, the modal can always expresses the modal force of possibility. The modal base for its modal readings comes from the circumstances the speaker refers to. Thus can followed by the 
simple aspect expresses root modality. The possible worlds are organized by: empty, permissive, boulomaic or abilitive ordering sources.

Secondly, in matrix predicates with the progressive aspect, the modal can always expresses the modal force of possibility. The modal interpretations may come from either circumstantial or epistemic modal bases. The former take: empty, permissive or abilitive ordering sources; whereas the latter are structured by: deductive or speculative ordering sources. A conclusion thus may be drawn that the progressive aspect may be a trigger of the epistemic modal readings of can (see also Szymański 2019).

Thirdly, the modal can in matrix predicates with the perfect aspect has been found to express the modal force of possibility or necessity. Both of them take epistemic modal bases, and either speculative or deductive ordering sources. We may thus conclude that the perfect aspect converges with the epistemic modality expressed by the modal can.

When it comes to the expressions of the modal force of necessity, they have been observed only in the utterances whose subjects are negated (see also Szymański 2019). These modal interpretations may be compared to such in which the modal auxiliary is negated. Consider the following example:

\section{(33) a. Few doctors nowadays can have seen a carbuncle like this.}

b. Many doctors can't have seen a carbuncle like this.

Both the sentences in (33) express the same level of speaker's certainty that not many doctors were able to see such a carbuncle. The modal reasoning in each of them results from the speaker's deduction or their knowledge, thus they express epistemic modality. We may, therefore, conclude that the modal can interacts with the negative subject in the same way as it does with the negation of the modal verb (de Haan 1997; Morante and Sporleder 2012; J.R. Payne 1985; T.E. Payne 1997). What is more, negation influences modality even though the negative element is not a constituent of the predicate.

The study adds one more important finding concerning the modality-grammatical aspect interaction to the vast body of topical literature. It has demonstrated that the grammatical perfect aspect with the modal can tends to trigger epistemic modal readings (see also Szymański 2015, 2016a, 2016b, 2017, 2019).

All in all, the above research outcome enhances our understanding of modalityaspect interplay, with the semantic field of the modal auxiliary can in particular. Aspect, however, is not only a grammatical category. Therefore, further research might explore patterns of interaction between modality and the semantic aspect, which takes the inherent semantic features of the main verb into account. 


\section{Notes}

1 All the information about the corpus included in this paper has been obtained from the corpus website.

2 The study described in this paper was conducted before the latest addition of texts to the corpus that took place in December 2017.

\section{References}

Abraham, Werner (2008) On the logic of generalizations about cross-linguistic aspect-modality links. In Abraham, Werner and Elisabeth Leiss (eds.) Modality-Aspect Interfaces: Implications and Typological Solutions. Amsterdam, Philadelphia: John Benjamins, 3-13.

Abraham, Werner and Elisabeth Leiss (eds.) (2008) Modality-Aspect Interfaces: Implications and Typological Solutions. Amsterdam and Philadelphia: John Benjamins.

Biber, Douglas, Johansson, Stig, Leech, Geoffrey, Conrad, Susan and Edward Finegan (1999/2007) Longman Grammar of Spoken and Written English. Harlow: Pearson Education Limited.

Binnick, Robert I. (1991) Time and the Verb: A Guide to Tense and Aspect. New York, Oxford: Oxford University Press.

Binnick, Robert I. (2002-2006) The Project on Annotated Bibliography of Contemporary Research in Tense, Grammatical Aspect, Aktionsart, and Related Areas. Scarborough: University of Toronto. Available at http://www.utsc.utoronto.ca/ binnick/TENSE/ (Accessed on 19 January, 2019).

Binnick, Robert I. (2005) The markers of habitual aspect in English. Journal of English Linguistics 33(4), 339-369.

Binnick, Robert I. (2006) Aspect and aspectuality. In: Aarts, Bas and April McMahon (eds.) The Handbook of English Linguistics. Malden, MA: Blackwell Publishing, 244-268.

Bybee, Joan, Perkins, Revere and Wiliam Pagliuca (1994) The Evolution of Grammar: Tense, Aspect, and Modality in the Languages of the World. Chicago and London: The University of Chicago Press.

Chrzanowska-Kluczewska, Elżbieta (2013) Literary semantics and literary pragmatics - (in)separable disciplines?. Biuletyn Polskiego Towarzystwa Językoznawczego 69, 77-94.

Comrie, Bernard (1976/2001) Aspect: An Introduction to the Study of Verbal Aspect and Related Problems. Cambridge: New York: Cambridge University Press.

Dahl, Östen (1985) Tense and Aspect Systems. Oxford: Blackwell.

Davies, Mark (2008-) The Corpus of Contemporary American English: 560 million words, 1990present. Available at http://corpus.byu.edu/coca/ (Accessed on 19 January, 2019).

de Haan, Ferdinand (1997) The Interaction of Modality and Negation. A Typological Study. New York and London: Garland Publishing, Inc.

Eckhoff, Hanne, and Dag Haug (2015) Aspect and prefixation in Old Church Slavonic. Diachronica $32(2), 186-230$.

Hacquard, Valentine (2009) On the interaction of aspect and modal auxiliaries. Linguistics and Philosophy 32, 279-312.

Hacquard, Valentine (2011) Modality. In: Maienborn, Claudia, von Heusinger, Klaus and Paul Portner (eds.) Semantics: An International Handbook of Natural Language Meaning. Berlin: Mouton de Gruyter, 1484-1515.

Hacquard, Valentine (2013) On the grammatical category of modality. In: Aloni, Maria, Franke, Michael and Floris Roelofsen (eds.) Proceedings of the $19^{\text {th }}$ Amsterdam Colloquium, 19-26.

Higginbotham, James (2009) Tense, Aspect and Indexicality. Oxford: Oxford University Press.

Hintikka, Jaakko (1962) Knowledge and Belief. Ithaca, NY: Cornell University Press.

Huddleston, Rodney D. and Geoffrey K. Pullum (2002) The Cambridge Grammar of the English Language. Cambridge: Cambridge University Press. 
Kotin, Michail L. (2012) Modalitäten. In: Pawłowski, Grzegorz, Olpińska-Szkiełko, Magdalena and Silvia Bonacchi (eds.) Mensch - Sprachen - Kulturen: Beiträge und Materialien der Internationalen Wissenschaftlichen Jahrestagung des Verbandes Polnischer Germanisten 25.-27. Mai 2012. Warszawa. Warszawa: Euro-Edukacja, 140-158.

Kotin, Michail L. (2014) Modalitäten im Sprachkontrast: Nochmals zu der Aspektualität-Modalität-Schnittstelle. In: Lukas, Katarzyna and Izabela Olszewska (eds.) Deutsch im Kontakt und im Kontrast: Festschrift für Prof. Andrzej Kątny zum 65. Geburstag. Frankfurt am Main: Peter Lang, 105-117.

Kratzer, Angelika (1977) What 'must' and 'can' must and can mean. Linguistics and Philosophy 1(3), 337-355.

Kratzer, Angelika (1991) Modality. In: von Stechow, Armin and Dieter Wunderlich (eds.) Semantics: An International Handbook of Contemporary Research. Berlin: de Gruyter, 639-650.

Kratzer, Angelika (2012) Modals and Conditionals: New and Revised Perspectives. Oxford and New York: Oxford University Press.

Lyons, John (1977) Semantics vol. 2. Cambridge: Cambridge University Press.

Morante, Roser and Caroline Sporleder (2012) Modality and negation: An introduction to the special issue. Computational Linguistics 38(2), 223-260.

Nuyts, Jan (2006) Modality: Overview and linguistic issues. In: Frawley, William (ed.) The Expression of Modality. Berlin: Mouton De Gruyter, 1-26.

Palmer, Frank R. (1979/1990) Modality and the English Modals. London: Longman.

Palmer, Frank R. (1986/2001) Mood and Modality ( $2^{\text {nd }}$ edition). Cambridge: Cambridge University Press.

Payne, John R. (1985) Negation. In: Shopen, Timothy (ed.) Language Typology and Syntactic Description vol. I: Clause Structure. Cambridge: Cambridge University Press, 197-242.

Payne, Thomas E. (1997) Describing Morphosyntax. Cambridge: Cambridge University Press.

Perzanowski, Jerzy (2006) Ontyka modalności. In: Strawiński, Witold, Grygianiec, Mariusz and Anna Brożek (eds.) Myśli o Języku, Nauce i Wartościach. Księga Ofiarowana Profesorowi Jackowi Juliuszowi Jadackiemu w Sześćdziesiątą Rocznicę Urodzin. Warszawa: Wydawnictwo Naukowe Semper, 281-297.

Portner, Paul (2009) Modality. Oxford: Oxford University Press.

Pruss, Alexander R. (2001) Possible Worlds: What They Are Good for and What They Are. Pittsburgh: University of Pittsburgh.

Quirk, Randolph, Greenbaum, Sidney, Leech, Geoffrey and Jan Svartvik (1985) A Comprehensive Grammar of the English Language. London and New York: Longman Group Limited.

Sasse, Hans-Jürgen (2002) Recent activity in the theory of aspect: Accomplishments, achievements, or just non-progressive state?. Linguistic Typology 6 (2), 199-271.

Smith, Carlota S. (1997) The Parameter of Aspect. Dordrecht: Kluwer Academic Publishers.

Sweetser, Eve E. (1982) Root and epistemic modals: causality in two worlds. In: Proceedings of the Eighth Annual Meeting of the Berkeley Linguistics Society (1982). Berkley, C.A.: Berkley Linguistics Society, 484-507.

Szymański, Leszek (2015) An empirical analysis of the semantic field of the English modal auxiliary verb 'may' in $19^{\text {th }}$-century American English exampled in the novel "Moby Dick; or, the Whale" by Herman Melville. Biuletyn Polskiego Towarzystwa Językoznawczego 71, 93-109.

Szymański, Leszek (2016a) The interaction of negated 'must' and grammatical aspect in contemporary American English - An empirical contribution to aspect-modality interaction studies. In: Hinton, Martin (ed.), Evidence, Experiment and Argument in Linguistics and the Philosophy of Language. Frankfurt am Main: Peter Lang Edition, 111-130.

Szymański, Leszek (2016b) Towards a transboundary approach to the analysis of linguistic modality - Elements of an empirical investigation of the modal auxiliary 'must' in contemporary American English. Biuletyn Polskiego Towarzystwa Językoznawczego 72, 211-229. 
Szymański, Leszek (2017) An empirical investigation of the allegedly non-normative modal predicate with 'must', 'not', and the perfect infinitive of the main verb. Biuletyn Polskiego Towarzystwa Językoznawczego 73, 247-258.

Szymański, Leszek (2017) Modal Auxiliaries and Aspect in Contemporary American English A Corpus-based Study. Zielona Góra: Oficyna Wydawnicza Uniwersytetu Zielonogórskiego.

Vendler, Zeno (1957) Verbs and times. The Philosophical Review, 66 (2), 143-160.

Vince, Michel (2009) First Certificate Language Practice. London: Macmillan.

von Fintel, Kai (2006) Modality and language. In: Borchert, Donald M. (ed.) Encyclopedia of Philosophy ( $2^{\text {nd }}$ edition). Detroit: Gale/Thomson Learning, 20-27.

LESZEK SZYMAŃSKI works at the Institute of Modern Languages, University of Zielona Góra, Poland. His research interests include: grammar-semantics interfaces, sociolinguistics, Internet linguistics, language change and corpus linguistics. Currently, he is investigating the interrelations between modality and aspect in contemporary American English.

Address: Leszek Szymański, Instytut Neofilologii, Uniwersytet Zielonogórski, al. Wojska Polskiego 71a, 65-762 Zielona Góra, Poland. [email: L.Szymanski@in.uz.zgora.pl] 